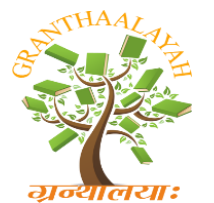

INTERNATIONAL JOURNAL OF RESEARCH GRANTHAALAYAH

A knowledge Repository

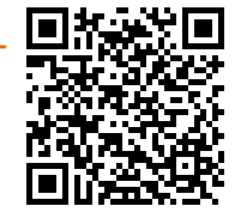

Social

\title{
THE PREVALENCE OF VITAMIN A DEFICIENCY AMONG CHILDREN BETWEEN 6- 9 YEARS OLD, EL FATEH QURAN SCHOOL, OMDURMAN LOCALITY, KHARTOUM STATE, SUDAN
}

\author{
Dr. Adam Abdalla Mater ${ }^{* 1}$, Nosyba Awad Said Taha ${ }^{2}$ \\ ${ }^{* 1}$ Assistant Professor, Faculty of Public Health, Alzaeim Alazhari University, SUDAN \\ ${ }^{2}$ Public Health Officer, Ministry of Health, Khartoum State, SUDAN
}

\begin{abstract}
There is a substantial documentation of prevalence, severity and health consequences of vitamin A deficiency (VAD) in preschool-aged children, very few studies have been done to find out the extent of VAD among Quran pupils. This was a cross-sectional descriptive analytical study conducted in Elfateh Quran School, Omdurman locality. The objectives were to measure the prevalence of Xerophthalmia among Quran pupils in El-Fateh city and to relate it with socio demographic factors.

All students between 6 to 9 years age in ELfatih Quran pupils were considered as target of this study, total coverage was done during the study period from(august to October)2012, and they were 220 students. Data was collected by using a questionnaire and eye examination to all students targeted age group. Data analyzed by using SPSS programs.

The study found that the prevalence of VAD was $19.1 \%$, of which $18.2 \%$ among boys which is significantly lowers than $0.9 \%$ among girls. The prevalence of night blindness was $7.3 \%$, Bitots spots were $4.1 \%$, corneal xerosis $5 \%$ and $2.7 \%$ were night blindness \pm eye sign.

The study concluded that the prevalence of VAD among study population was (19.1\%). Institutional caregivers should be made aware of the importance of providing a balanced diet rich in vitamin A. They should also be aware of the signs and symptoms of VAD for early detection of xerophthalmia and hence take measures of early treatments.
\end{abstract}

Keywords:

Vitamin A Deficiency, Children, severity and health, Public Health.

Cite This Article: Dr. Adam Abdalla Mater, and Nosyba Awad Said Taha, "THE PREVALENCE OF VITAMIN A DEFICIENCY AMONG CHILDREN BETWEEN 6- 9 YEARS OLD, EL FATEH QURAN SCHOOL, OMDURMAN LOCALITY, KHARTOUM STATE, SUDAN" International Journal of Research - Granthaalayah, Vol. 4, No. 4 (2016): 97 102. 


\section{INTRODUCTION}

Vitamin A deficiency is lack of vitamin A in humans. It is common in poorer countries but rarely seen in more developed countries that are wealthier. Night blindness is one of the first signs of vitamin A deficiency. Xerophthalmia, keratomalacia, and complete blindness can also occur since Vitamin A has a major role in photo transduction. Approximately 250,000 to 500,000 malnourished children in the developing world go blind each year from a deficiency of vitamin A, approximately half of whom die within a year of becoming blind. The United Nations Special Session on Children in 2002 set the elimination of vitamin A deficiency by 2010 (WHO, 2008).

Today, 30 per cent of all deficient children are thought to live in Africa (world nutrition, 2010). Recent calculations show that nearly 250 million preschool children are sub clinically vitamin A deficient - this is almost 50\% of those in developing countries. Three million have xerophthalmia at any one time; about $90 \%$ of these suffer from night blindness and other nonblinding xerophthalmia. $10 \%$ or 300,000 are blind with keratomalacia and this account for about $10 \%$ of all blind children in the world. (Donals et al, 2001).

Vitamin A deficiency affect about $25 \%$ of young children with equatorial Africa (and probably Southern Sudan) having some of the highest rates causes about $6 \%$ of young child deaths (Purges, 2008).

Approximately 250,000-500,000 children in developing countries become blind each year owing to vitamin A deficiency, with the highest prevalence in Africa. According to the World Health Organization (WHO), vitamin A deficiency is under control in the United States, but in developing countries vitamin A deficiency is a significant concern.

The diet provided to the children at the "Quran schools" is mostly nutritionally deficient in vitamin A (Kheir, et al, 2012).

Hunger and inadequate food supply are still affecting large parts of the world's population. They have serious effects on health and well-being, especially among children. Under nutrition and malnutrition in childhood interfere with physical and mental development, thus compromising whole lives. Assuring adequate nutrition from an early age is therefore a prerequisite for a society's prosperity. Diet plays a special role because of the importance of specific micronutrients for growth and development. Nonetheless, studies on vitamin A deficiency among children in Sudan are few. Further investigations and surveys are needed for authentic documentation and suggestions on possible solutions. Again all studies conducted were restricted to the age group of children between 72 months and less than nine years. All such investigations were conducted in areas with low socio-economic status and poor or lack of health services. So far, little investigations were carried out in areas with pockets of populations with low socioeconomic status riving amongst communities of high socio-economic status.

The objectives were to measure the prevalence of Xerophthalmia among Quran pupils in El Fateh and to relate it with socio demographic factors. 


\section{METHODOLOGY}

This was a descriptive cross- sectional study conducted in El Fatehcity; Omdurman locality. The study targeted all pupils between six to nine years old resides in the Quran school, They eat the same food in the same time by total coverage. Which are 11 Quran school. All pupils covered by the study their aged between $(6-9)$ years old.

All targets pupils were interviewed. Specific questionnaire was designed to collect nutritional knowledge and factors associated with vitamin a deficiency. The questionnaire include the following variables; age, sex, feeding practice of children in addition to family income, infection with diarrhea, fever, acute respiratory tract, malaria, and measles.

All the children were examined in day light for vitamin A deficiency. Xerophthalmia was diagnosed if there was history of night blindness, or there were signs of conjunctival xerosis, Bitot's spots, corneal xerosis and keratomalacia on clinical examination. Only night blindness, corneal xerosis and Bitots spots were found by this survey. Dietary intake of dark green leafy vegetables/yellowish fruits noted in terms of frequency consumption per week percentiles were calculated for each respective age group. Eye examination do by nutritionist had high training in xerophthalmia diagnosing. To assess the nutritional status of pupils, weights and heights were measured according to standard procedures described by WHO, 2007. Data were analyzed by the computer software and different statistical tests were used to determine the significance by using 95 confidence level.

\section{RESULTS}

Complete data were obtained from all pupils $(6-9)$ years old reside in 11Quran School in this study. A total of 220 children were measured and interviewed. Only 44(20\%) were (6-7) years, $95(43.2 \%)$ were $(7-8)$ years and $81(36.8 \%)$ were $(8-9)$ years old.

The study group comprised 209(95\%) males and 11(5\%) females. With regard to father occupation 13(5.9\%) were unemployment, 74(33.7\%) were employer, 57(25.9\%) were merchant and $76(34.5 \%)$ were unskilled labor. The majority of our study group 135(61.4\%) had monthly income less than 500SDG, 83(37.7\%) had 500 - less than 1000SDG monthly income and 2(.9\%) had monthly income more than 1000SDG family income.

Table 1: Socio demographic profile of the study population, El-Fateh city Quran schools, Omdurman locality.

\begin{tabular}{|c|c|c|}
\hline \multicolumn{3}{|c|}{$\mathrm{N}=220$} \\
\hline Variables & Number & $\%$ \\
\hline Age $6->7$ years & 44 & $20 \%$ \\
\hline $7 \rightarrow$ 8years & 95 & $43.2 \%$ \\
\hline $8-9$ years & 81 & $36.8 \%$ \\
\hline $\begin{array}{ll}\text { Sex } & \text { male } \\
& \text { Female }\end{array}$ & $\begin{array}{l}209 \\
11\end{array}$ & $\begin{array}{l}95 \% \\
5 \%\end{array}$ \\
\hline
\end{tabular}




\begin{tabular}{|l|l|l|}
\hline & & \\
\hline Father occupation & 13 & $5.9 \%$ \\
Unemployed & 74 & $33.7 \%$ \\
Employer & 57 & $25.9 \%$ \\
Merchant & 76 & $34.5 \%$ \\
Un skilled laborer & & \\
\hline Monthly income & 135 & $61.4 \%$ \\
Less than 500SDG & 83 & $37.7 \%$ \\
$500-1000$ SDG & 2 & $.9 \%$ \\
More than 1000SDG & & \\
\hline Mother education & 5 & $2.3 \%$ \\
Illiterate & 106 & $48.2 \%$ \\
Basic school & 109 & $49.5 \%$ \\
Secondary school & & \\
\hline
\end{tabular}

Table 2: Prevalence of VAD, El-Fateh city Quran schools Omdurman locality.

\begin{tabular}{|l|l|l|}
\hline VAD & Number & $\%$ \\
\hline $\begin{array}{l}\text { Positive night blindness } \\
\text { and/or eye sign }\end{array}$ & 42 & $19.1 \%$ \\
\hline Negative & 178 & $80.9 \%$ \\
\hline Total & 220 & $100 \%$ \\
\hline
\end{tabular}

Table 3: VAD by sex, El Fateh city Quran schools, Omdurman locality.

\begin{tabular}{|c|c|c|c|c|c|c|}
\hline \multicolumn{7}{|c|}{$\mathrm{N}=220$} \\
\hline \multirow{3}{*}{ Sex } & \multicolumn{4}{|c|}{ VAD } & \multirow{2}{*}{\multicolumn{2}{|c|}{ Total }} \\
\hline & \multicolumn{2}{|c|}{ Positive } & \multicolumn{2}{|c|}{ Negative } & & \\
\hline & No & $\%$ & No & $\%$ & No & $\%$ \\
\hline Male & 40 & 19.1 & 169 & 80.9 & 209 & 95 \\
\hline Female & 2 & 18 & 9 & 81 & 11 & 5 \\
\hline Total & 42 & 19.1 & 178 & 80.9 & 220 & 100 \\
\hline
\end{tabular}


Table 4: Relationship between VAD children's and father occupation in El-Fateh city Quran schools, Omdurman locality.

$\mathrm{N}=220$

\begin{tabular}{|c|c|c|c|c|c|c|}
\hline \multirow{3}{*}{ Father occupation } & \multicolumn{4}{|c|}{ VAD } & \multirow{2}{*}{\multicolumn{2}{|c|}{ Total }} \\
\hline & \multicolumn{2}{|c|}{ Positive } & \multicolumn{2}{|c|}{ Negative } & & \\
\hline & No & $\%$ & No & $\%$ & No & $\%$ \\
\hline Unemployed & 5 & 38.5 & 8 & 61.5 & 13 & 5.9 \\
\hline Employer & 27 & 36.5 & 47 & 63.5 & 74 & 33.7 \\
\hline Merchant & 6 & 10.5 & 51 & 89.5 & 57 & 25.9 \\
\hline Unskilled labor & 4 & 5.3 & 72 & 94.7 & 76 & 34.5 \\
\hline Total & 42 & 19.1 & 178 & 80.9 & 220 & 100 \\
\hline
\end{tabular}

Table 5: The nutrition status in study group, Quran schools.

$\mathrm{N}=220$

\begin{tabular}{|l|l|l|}
\hline Nutrition status & Number & $\%$ \\
\hline Normal N S & 58 & 26.4 \\
\hline Mild N S & 73 & 33.2 \\
\hline Moderate N S & 53 & 24.1 \\
\hline Sever N S & 36 & 16.3 \\
\hline Total & 220 & 100 \\
\hline
\end{tabular}

Table 6: Relationship between VAD and nutrition status in study group, Quran schools. $\mathrm{N}=220$

\begin{tabular}{|l|l|l|l|l|l|l|}
\hline \multirow{2}{*}{ Nutrition status } & \multicolumn{3}{|l|}{ VAD } & \multirow{2}{*}{ Total } \\
\cline { 2 - 7 } & \multicolumn{3}{|l|}{ Positive } & Negative & \multicolumn{2}{l|}{} \\
\cline { 2 - 7 } & No & $\%$ & No & $\%$ & No & $\%$ \\
\hline Normal N S & 7 & 12.1 & 51 & 87.9 & 58 & 26.4 \\
\hline Mild N S & 10 & 13.7 & 63 & 86.3 & 73 & 33.2 \\
\hline Moderate N S & 0 & 0 & 53 & 100 & 53 & 24.1 \\
\hline Sever N S & 25 & 69.4 & 11 & 30.6 & 36 & 16.3 \\
\hline Total & 42 & 19.1 & 178 & 80.9 & 220 & 100 \\
\hline 53.225 & df 1 & $\mathrm{p}=.000$ & & & \\
\hline
\end{tabular}

\section{DISCUSSION}

The prevalence rate of vitamin a deficiency among children between six and less than nine years was $(19.1 \%)$. this appeared according to the eye examination, were conceder a public health problem , according to Sommer and Davidson, 2002. define significant prevalence as night blindness $>1 \%$ or Bitot spots $>.5 \%$ as a problem . 
Also survey was conducted to estimate vitamin a deficiency prevalence rate in 220 children in Quran schools between six and less than nine years. is (18.2\%) male higher than (.9\%) female there were no statistically significant association $(\mathrm{p}=.098)$ because is inconstant disagree with Donals a et al, 2001 .Said that It has been found that for all aspects of VAD males are more susceptible than females.

There were no significant association $(\mathrm{p}=.389)$ between those affected with vitamin a deficiency and age distribution According to Maha and others, 2012. Study result No significant association was observed between the differences in mean age and development of night blindness.

This result reflected that no statistically significant association between those children affected with vitamin a deficiency and their families monthly income ( $\mathrm{p}=.081)$ above fifty pupils incomes were low. Dietary quality can be affected by market prices of micronutrient-rich foods. Johns, 2010.

The result reflects highly significant association between nutrition status and VAD had. ( $p$ $=.000)$. In more recent years, various vitamin and mineral deficiencies, including vitamin $\mathrm{A}$, iron, iodine and zinc have been recognized as discrete types of mal- nutrition that adversely affect human health and contribute to disease and mortality related to Shankar, 2001.

\section{REFRENCES}

[1] Abdelmoneim E. M. Kheir et al. 2012. Xerophthalmia in a Traditional Quran Boarding School in Sudan, Middle East Africa Journal, 19 (2): 190-193. BMC335366.

[2] Ann purges, 2008. Mother and child under nutrition - vitamin a deficiency, south Sudan medical journal.

[3] American institute of nutrition, 2010. Vitamin A Intake and Status in Populations Facing Economic Stress, nutrition journal, Center for Human Nutrition, Department of International Health, Johns Hopkins Bloomberg School of Public Health, Baltimore, MD 21205, volume 140. no 1

[4] American Society for Nutrition journal, 2008. Nutrition. vol. 138 no. 10 1835-1839.

[5] Black RE et al., Maternal and child under nutrition: global and regional exposures and health consequences, The Lancet, 2008, 371(9608), p. 253. Bulletin of the World Health Organization, 2001, 79: 415-422.

[6] Donalds.Mclaren, MD, PhD, FRCPand Martin fig, 2001. Vitamin a in health and disease. Sight and life guide book.second edition, ISBN 3-906412-07-5

[7] Dr. Alfred Sommer, MD, MHS, 2011. Vitamin a deficiency disorder, The Johns Hopkins University Bloomberg School of Public Health.

[8] Eduardo Villamor and Wafaie W. Fawzi, 2005. Effects of Vitamin A Supplementation on Immune Responses and Correlation with Clinical Outcomes, clinical microbio jurnal, volum 18 issue 3 page 446 - 464.

[9] E. Kala Ranjini, Thomas Cherian, K.A. Balasubramaniam, P. Raghupathy, 2001. Vitamin a supplementation in children with recurrent respiratory infections, indian pediatrics.

[10] Elana Pearl Ben-joseph. MD, 2012. For specific medical advice, diagnoses, and treatment, consult your doctor, educational purposes. 